\title{
The Impacts of Open/closed Body Positions and Postures on Learners' Moods
}

\author{
Mohammad Zabetipour \\ Ferdowsi University of Mashhad, Iran \\ E-mail:m.zabetipour@gmail.com \\ Reza Pishghadam \\ Ferdowsi University of Mashhad, Iran \\ E-mail: pishghadam@um.ac.ir (Corresponding author) \\ Behzad Ghonsooly \\ Ferdowsi University of Mashhad, Iran \\ E-mail:ghonsooly@um.ac.ir
}

\section{Doi:10.5901/mjss.2015.v6n2s1p643}

\section{Abstract}

\begin{abstract}
When humans feel confident, lively, and active, they assume an open expansive posture, however when they feel helpless, insecure, and listless, they assume a closed and contractive posture. Hence, the question is whether open or closed postures affect EFL learners' moods. This study would highlight the impacts of the bodily behaviors on the person assuming specific physical postures and is aimed at revealing the possible impacts of high/low power (open/closed) sitting postures on language learners' moods. To this aim, 15 male Iranian English learners were asked to assume open, closed, and ordinary postures in nine 90-minute sessions. The data were collected through using a questionnaire and the participants' self-narratives. The statistical analysis of the questionnaire and qualitative analysis of the self-narratives demonstrated that closed postures have more negative impacts on moods while open postures have more positive impacts.
\end{abstract}

Keywords: Closed posture; high-power posing; low-power posing; open posture

\section{Introduction}

When it comes to communication, the transmission of information/signals from a source to a destination (Richards \& Schmidt, 2002), at first, everyone thinks of it as to be a totally verbal act, while Mehrabian (1972, as cited in Osho, 2011) has shown that $93 \%$ of communication is nonverbal, while only $7 \%$ of it is verbal. Similarly, Birdwhistell (1952, as cited in Pease, 1981) who coined the term Kinesics stated that non-verbals account for over 65 percent of communication. Mehrabian (1971) holds the view that body language, gestures, and postures are of high importance that when, for instance, our verbal messages contradict the nonverbal and silent messages used simultaneously, our interlocutors mistrust what we say. Given these ideas, pose and gesture analysis plays an important role in various fields and applications such as gestural-based phonology (e.g., Docherty \& Ladd, 1992), human-machine interaction (e.g., Nielsen, Canalís, \& Tejera, 2004), gesture, race, and culture studies (e.g., Efron, 1972) second/foreign language teaching and learning (e.g., Gregersen, 2007; Gullberg, 2010; Kendon, 2000; Macedonia \& Kriegstein, 2012; Taleghani, 2008), portrait photography (e.g., Smith, 2004), and even motion capture for the entertainment industry (e.g., Corazza et al., 2006).

Moreover, the fact that how our nonverbal behaviors (gestures and postures) help others read our feelings and thoughts has received a great deal of attention as there's a long literature exploring the roles bodily movements and postures play in interpersonal communication (e.g., Clay, Couture, \& Nigay, 2007; Dael, Goudbeek, \& Scherer, 2013; D'Mello, Chipman, \& Graesser, 2007; Ekman, 1999; Izard, 1994; McHugh, McDonnell, O'Sullivan, \& Newell, 2010; Mehrabian, 1971; Mota \& Picard, 2003; Neill \& Caswell, 1993; Nierenberg \& Calero, 1971; Pease, 1981). For instance, there is an assumption between politicians, consultants, and journalists saying that nonverbal behaviors of political leaders influence audiences' perceptions of them (Nagel, Maurer, \& Reinemann, 2012).

All of the aforementioned studies imply that physical posture and human poses help the interlocutor understand better what his interlocutor says and feels in any communication. But the fact is that when people think of nonverbals, 
they often think how they judge others, and how others judge them; indeed, they forget the other audience that is also affected by their nonverbals, and that is themselves.

Hence, the fact that how physical postures, gestures, and poses affect the person assuming them has also been under scrutiny by numerous scholars who believe that a change in our physical postures and gestures can bring about changes in our thoughts, moods, and feelings (e.g., Arnette \& Pettijohn, 2012; Brinol, Petty, \& Wagner, 2009; Carneym Cuddy, \& yap, 2010; Cesario \& McDonald, 2013; Cuddy, Wilmuth, \& Carney, 2012; Flack, Laird, \& Cavallaro, 1999; Laird, 1974; McIntosh, 1996; Riskind \& Gotay, 1982; Rossberg-Gempton \& Poole, 1993; Schnall \& Laird, 2003; Stepper \& Strack, 1993). According to Harmon-Jones and Peterson (2009), emotional processes are affected by body movements. People usually express their feelings and moods through facial expressions and consistent bodily postures as well as vocal expressions and gestures (Flack, Laird, cavallaro, \& Miller, 1989). Likewise, Churches and Terry (2007) hold the view that there's a mutual and internal relationship between internal states, internal processing, and external behaviors of people.

Keeping this in mind, in both humans and animals, possessing high-power is reflected through open, expansive postures while having low-power is reflected through closed, contractive ones (Carney, Hall, \& Smith LeBeau, 2005). Not only do these postures reflect power, but also they produce it. Chiefly, assuming a high-power posture is associated with elevation of feelings of power, risk-taking, pain tolerance, and secretion of testosterone hormone, as well as reduction of stress, anxiety, and secretion of cortisol hormone (Carney et al., 2010). On the other hand, low or reduced power is associated with being subject of more threat, punishment and social restriction, systematic cognition, situationally constrained behavior, sensitivity to how other people evaluate them (Keltner, Gruenfeld, \& Anderson, 2003), activation of the inhibition system (Anderson \& Galinsky, 2006; Keltner et al., 2003) self-censorship, inhibition in expressing oneself, more negative emotion, feeling more anger and decreased gestural activity (Andersen \& Berdahl, 2002).

However, recent studies have shown that the mental state of power is not only related to hierarchical roles, but it is related to the body, too (Huang, Galinsky, Gruenfeld, \& Guillory, 2011). Indeed, body expansiveness in both humans and animals is related to dominance (Carney et al., 2010), and recent studies have also shown that open postures produce power-related feelings (Tiedens \& Fragale, 2003), cognitions (Riskind \& Gotay, 1982), and cause changes in two key hormones hormone associated with powerfulness and powerlessness (Carney et al., 2010).

The researches to date have not given enough attention to how physical postures and gestures may facilitate language learners' emotional states in a language classroom. Assuming this, making use of body postures and positions in a language classroom will probably have impact on students' moods since as Brown (2000) states, psychological and personality, or in other words, affective factors such as anxiety, motivation, risk taking, self-esteem, and extroversion within a person play crucial roles in language learning. On the other hand, Carney et al. (2010) indicated that our body posture, power posing, can affect anxiety and risk taking levels in the brain.

Hence, this study aims to investigate if the positions and postures learners take in a language classroom has impact on their moods and if their body position can be regarded as a tool to overcome negative moods. It was assumed that when language learners are induced to assume a high-power pose, the students feel confident, and when they are induced to assume a low-power pose, they experience anxiety. It is also important to note that to the present study researchers' knowledge, this study is the first attempt focusing on the impacts of high/low-power posing or closed/open sitting poses on learners' moods in the realm of language learning and teaching.

\section{Literature Review}

How is it possible that one feels romantic attraction as he/she gazes to his/her opposite sex? Why do we feel happy when we laugh and feel angry when we scowl? Why do both humans and animals seem to slump or hunch their body when they feel powerless and face failure? And why do they rise up and assume an upright posture when they feel powerful and experience success or victory?

Based on the embodied cognition theory, cognitive and emotional processes are rooted in the body's interactions with the world (Wilson, 2002), and according to Cesario and McDonald (2013, p. 261) there is "a direct connection involving a stored, context-independent association between particular physical positions of the body and corresponding psychological states". In other words, there's a mutual and internal relationship between internal states, internal processing, and external behaviors of people (Churches \& Terry, 2007). It means that our thoughts, our feelings, and our physiology are also affected by our gestures, postures, and nonverbals (Carney et al., 2010; Cuddy et al., 2012; Riskind \& Gotay, 1982). For instance, based on an underlying assumption of dance therapy, bodily behaviors and changes can cause emotions (Rossberg-Gempton \& poole, 1993).

Basically, a certain posture can have impact on the emotions of the person assuming that posture (Rossberg- 
Gempton \& Poole, 1993). Similarly, Duclos, Laird, Schneider, Sexter, Stern, and Van Lighten, (1989) hold the view that the experience of an emotion is the result of bodily changes and actions during an emotional event. For instance, human beings assume an expansive posture after victory and success while they adopt a slumped posture in case of failure and defeat (Riskind, 1984) which shows that there is a connection between the body and the mind. Schnall and Laird (2003) assert that bodily activities such as facial expressions, postures, and gestures have impact on our emotional states and feelings. That is to say, if we pretend that we are happy, and we will feel happy, and if we pretend that we are angry, we will feel angry (Schnall \& Laird, 2003).

The works of Darwin (1890), theories of James (1980), and Hegel (1971), can be regarded as to be the pioneers of investigating the impacts of emotional and physical behavior on emotional experience. For instance, James takes the stance that changes in emotional experiences are caused by bodily activities. James (1980) holds the view that a number of bodily responses can elicit emotional experiences. In an earlier work, James (1932, as cited in Rossberg-Gempton \& Poole, 1993) asked his participants assume specific postures and report their emotions. The results revealed that assuming certain postures produce a muscular strain that could not be identified by the same participants viewing these postures being held by others. In addition, for instance, Bernstein (1973) noted that open bodies release memories, moods, and emotions while closed bodies indicate that the person tends to have less contact with the environment. Similarly, Darwin (1890) says:

He who gives way to violent gestures will increase his rage; he who does not control the signs of fear will experience fear in a greater degree; and he who remains passive when overwhelmed with grief loses his best chance of recovering elasticity of mind. (p. 386)

Darwin (1890) holds the view that the way one expresses his or her emotion has impact on his or her emotional state. Recent studies have also confirmed that bodily positions and postures have been shown to elicit related affects, attitudes, and evaluative judgments (e.g., Carney et al., 2010). Besides, Brinol et al. (2009) state that body postures has impact on the motivation and one's ability to think in self-unrelated domains. For instance, Riskind and Gotay (1982) found that closed and slumped body postures decrease the amount of thinking related to different cognitive tasks.

\subsection{Gestures, Postures and Emotional Experiences}

According to Harmon-Jones and Peterson (2009), emotional processes are affected by body movements. People usually express their feelings and moods through facial expressions and consistent bodily postures as well as vocal expressions and gestures (Flack et al., 1989). Likewise, Arnette and Pettijohn (2012) take the stance that the body too may affect the mind to a greater extent than was recognized before. For instance, they maintain that "firming or flexing one's muscles can help to firm or strengthen the individual's willpower" (p. 9).

Hence, the fact that a person's postures can have feedback impacts on his or her moods and inner states has been implied in a number of studies (Anderson \& Galinsky, 2006; Carney et al., 2010; Cesario \& McDonald, 2013; Cuddy et al., 2012; Huang et al., 2011; Riskind \& Gotay, 1982; Rossberg-Gempton \& Poole, 1993; Tomkins, 2008). For instance, James (1922, as cited in Riskind \& Gotay, 1982) hypothesized, that physical bodily changes, e.g., postures, and emotional experiences are innately related to each other. Assuming this, "for James, physical bodily changes are the emotion and are critical cues for the emotion; thus, a person doesn't cringe because he/she is frightened, but rather, the person knows he/she is frightened because he/she notices that his/her body is cringing" (Riskind \& Gotay, 1982, p. 275). Riskind and Gotay (1982) showed that the participants who assumed a hunched posture for several minutes faced with higher levels of helplessness while solving a cognitive task. Similarly, assuming an open, expansive posture has impacts on cognitive processing, too, and in comparison with those who assumed a close restrictive posture, open body posers experienced more power-related words on a word completion task (Huang et al., 2011).

In the same vein, Rossberg-Gempton and Poole (1993) investigated the impacts of open and closed body postures on the emotional experiences of the person assuming the postures. The results of their study indicated that those assuming open postures experienced a slight reduction in pleasant emotions while those assuming a closed posture experienced an increase in unpleasant emotions. It is also important to note that in their study, Rossberg-Gempton and Poole (1993) found out that in comparison with males, females experienced a greater increase in unpleasant emotions when assuming a closed posture. They also state that the reduction of pleasant emotions of those assuming an open posture might be due to this fact that open postures were probably physically uncomfortable, foreign, and non-habitual for subjects. 


\subsection{Power and power posing}

Power is defined as the capacity to affect other people and it is related to the control over important sources and the ability to manage and organize rewards and punishments (Emerson, 1962, as cited in Anderson \& Galinsky, 2006). Accordingly, people pay a lot of attention, think about, and discuss the thoughts and behaviors of those who are in power and are powerful because in comparison with those who are not in power, power holders' actions have greater impact (Anderson \& Galinsky, 2006).

\subsubsection{High-power posture vs. Low-power posture}

In both humans and animals, possessing high-power is reflected through open, expansive postures while having lowpower is reflected through closed, contractive ones (Carney et al., 2005). Not only do these postures reflect power, but also they produce it. Chiefly, assuming a high-power posture is associated with elevation of feelings of power, risk-taking, pain tolerance, and secretion of testosterone hormone, as well as reduction of stress, anxiety, and secretion of cortisol hormone (Carney et al., 2010). Moreover, high-power postures have greater impacts on thought abstraction and action orientation (Huang et al., 2011). Surprisingly, acquiring power leads to specific behavioral and mental changes that can improve one's performance in social evaluation (Cuddy et al., 2009). First and most importantly, power has great impacts on one's performance in cognitive tasks that can cause him or her to appear more intelligent and organized (Guinote, 2007). Powerful people have higher self-esteem, praise, and positive attention as well as more access to financial resources and physical comforts (French \& Raven, 1959). In a number of studies where the participants were assigned to high-power posture conditions, it was found out that in comparison with those who were in low-power condition, highpower posers could experience more positive emotion, pay more attention to positive information, and express themselves easier and far more better in social relations and interactions (Anderson \& Berdahl, 2002; Smith \& Bargh, 2004). Moreover, high levels of power are associated with elevation of optimism in viewing risks and engagement in risky behavior (Anderson \& Galinsky, 2006). Elevated power is also associated with constructing others as a means to one's own goals and more willingness to engage in action (Keltner et al., 2003). Furthermore, in comparison with lower power people, those with higher power tend to be more extraverted, talk more and interrupt others more (Anderson, John, Keltner, \& Kring, 2001).

With regard to the nonverbal cues of high powered people, it is important to note that they make use of more eye contact, have more open and expansive postures, and more erect postures as well (Carney et al., 2005). Hence, assuming an erect expansive posture is often associated with having high power (Cuddy et al., 2010), and power-related feelings (Riskind \& Gotay, 1982). High-power posing also reduces stress, negative emotions, anxiety, and would make a person more eager, confident, and captivating (Anderson \& Berdahl, 2002; Carney et al., 2010).

On the other hand, low or reduced power is associated with being subject of more threat, punishment and social restriction, systematic cognition, situationally constrained behavior, sensitivity to how other people evaluate them (Keltner et al., 2003), activation of the inhibition system (Anderson \& Galinsky, 2006; Keltner et al., 2003) self-censorship, inhibition in expressing oneself, more negative emotion, feeling more anger and decreased gestural activity (Andersen \& Berdahl, 2002). It is also found out that not only are people with low power given few chances to speak, but also they themselves reject speaking when given the chance (Andersen \& Berdahl, 2002). Even more dramatic, Upmanyu (1974, as cited in Andersen \& Berdahl, 2002) states that children with lower social status show higher levels of negative moods, guilt, and depression.

Assuming this, power is expressed through specific nonverbal displays. While open, expansive postures display possessing high-power, closed, slumped ones project low power (Carney et al., 2010). However, the research to date has shown that power generates these two opposite patterns, but is it possible to say that these displays generate power? Will assuming a high power posture cause power? And will adopting a low power posture make the person feel powerless?

Carney et al. (2010) tried to find the answer of this question: can high/low power poses actually cause power? In order to answer it, Carney et al. (2010) randomly assigned forty two male and female participants to high-power or lowpower posture groups. None of the participants were aware of the nature of the experiment. The members of the highpower posture group were asked to assume two open and expansive postures each for one minute. On the other hand, the participants of low-power posture group were asked to assume two closed, hunched postures each for minute. In order to measure the testosterone and cortisol hormones levels, saliva samples were taken both before and after the treatment as pretest and posttest. Moreover, in order to measure the level of risk tolerance, participants were asked to take part in gambling; each person was given $\$ 2$ and was told that it would be possible to win $\$ 4$ during the game. At last, 
the participants indicated how powerful they felt by filling out a scale from one to four.

The results of Carney et al.'s (2010) experiment showed that those assuming high-power poses experienced elevation in secretion of testosterone hormone (power hormone) by about 20 percent increase and also a 25-percent decrease in secretion of cortisol hormone (stress hormone). On the contrary, low-power people experienced a 10-percent decrease in secretion of their testosterone hormone and also elevation in secretion of cortisol hormone by about 15 percent increase. Moreover, with regard to the measurement of risk taking levels, it was found out that 86 percent of the participants who were in high-power posture condition took the risk of gambling while only 60 percent of those who were in low-power posture condition gambled. Not surprisingly, high-power posture group also reported higher levels of being powerful.

In sum, as reviewed in this paper, the researches to date have not given enough attention to how physical postures and gestures may facilitate language learners' emotional states in a language classroom. Hence, this study would highlight the impacts of specific physical postures and bodily behaviors, high/low power posing, on moods of the students in a language classroom. According to the self-perception theory of Bem (1972) and Laird (1974), feeling states can be induced by changes in people's bodily activities. In the same vein, Duclos et al. $(1989$, p. 100) hold that "when people are induced to act happy, they feel happier" and "when people are induced to act angry, they feel angrier".

Thus, it is assumed in this study that if a language learner assumes a high or a low power pose, these physical postures may have positive or negative impacts on him. In other words, assuming a high-power pose will increase the secretion of testosterone hormone (risk-taking level) and decrease the secretion of cortisol hormone (anxiety level) (Carney et al., 2010). According to Ronay and Hipple (2010) power influences individuals' risky decision-making, and "higher levels of testosterone are associated with the pursuit of status seeking, dominance, competition, and violence" ( $p$. 474). Moreover, studies have indicated that sitting slumped in a chair can make people giving up more quickly on difficult cognitive tasks (Riskind \& Gotay, 1982). Similarly, Bernstein (1973) take the stance that closed body postures (folded arms and crossed legs) make people have little contact with the environment. Therefore, applying this method and highpower postures in a language classroom will probably have positive impacts on learners' moods.

\section{Research Methodology}

\subsection{Participants}

Fifteen male EFL learners aged from 15 to 25 participated in this study. They were all studying English in the same class at a language institute in Mashhad, Iran and were in the same level of language proficiency confirmed based on an achievement test. It is also important to note that at the beginning of the semester, there were about $25 \mathrm{EFL}$ learners in the same level, but only these fifteen students were chosen for the study because they had almost achieved similar scores in their previous semester's achievement test. Most of them were high-school students $(n=12)$, while the other three ones were university students studying nursing $(n=1)$, civil engineering $(n=1)$, and architecture $(n=1)$. The study utilized a within-subject experimental design. By comparing the effects of the different class types within the same participants, we could determine whether changes in self-reported moods from before to after a session would vary as a function of the specific focus on a given posture.

\subsection{Instruments}

Data for the study had been collected through using two different methods and instrumentations; the participants' selfnarratives and the Global Mood Scale (GMS) (Denollet, 1993) containing 20 mood descriptive adjectives (e.g., bright, active, tired, relaxed, and fatigued) that assessed their feelings. The GMS had a well-documented validity and reliability which was distributed at the beginning and at the end of each nine sessions of the experiment as pretests and posttests. GMS was validated through using Pearson's correlations and scale level factor analysis, and its reliability was reported to be 0.90 utilizing Cronbach alpha, while the reliability achieved in this study was 0.93 . In addition, the participants themselves described their feelings by submitting their own self-narratives. The data collection procedure (Table 1.) and data analysis procedure (Table 2.) are presented in the following, too. 
Table 1. The experiment procedure

\begin{tabular}{|c|c|}
\hline Treatment Sessions & Posture assumed \\
\hline Session 1 & Ordinary posture (Free posture) \\
Session 2 & High-power posing (open posture) \\
Session 3 & Low-power posing (closed posture) \\
Session 4 & Ordinary posture (Free posture) \\
Session 5 & High-power posing (open posture) \\
Session 6 & Low-power posing (closed posture) \\
Session 7 & Ordinary posture (Free posture) \\
Session 8 & High-power posing (open posture) \\
Session 9 & Low-power posing (closed posture) \\
\hline
\end{tabular}

The data collection procedure was done in nine sessions in which three different types of postures were compared: ordinary posture, high-power posture, and low-power posture. Each 90-minute class focused on one of the three types of poses with three repetitions of each type of posture. As a matter of fact, assuming a totally open or closed posture may have been physically uncomfortable, foreign, and non-habitual for some participants. Thus, the participants were asked to take an open/closed posture for 15 minutes, then, take a rest for 5 minutes and again assume the posture. In sum, each posture was examined three times, or in other words, in three sessions. The logic behind choosing three sessions for investigating each posture was the fact that it was impossible to truly examine each posture in only one or even two sessions because it was predicted that there might be some occasions and sessions when the participants might be totally upset or cheerful and not feel well and normal before coming to the class.

As shown in Table 1, in the first, fourth, and seventh sessions of the experiment students were asked to sit on their seats as they wish and assume any posture they liked and be in their usual postures. It was called the ordinary or free posture; the way they regularly used to sit on their seats in any classroom. The second, fifth, and eighth sessions were devoted to high-power posing. In fact, the participants were asked to assume a high-power (open) sitting posture. And finally, in the third, sixth, and ninth sessions, the participants were asked to assume a low-power (closed) posture. Before and after all of these sessions, the participants filled out the GMSs as pretests and posttests. In addition, they submitted their own self-narratives at the end of each session in which they had expressed their feelings and moods.

Table 2. Data analysis Procedure

\begin{tabular}{|c|c|c|}
\hline & Statistical Test & Variables \\
\hline Step 1 & One-sample T-tests & Pretest \& Posttest of each session \\
\hline Step 2 & One-way ANOVA & $\begin{array}{l}\text { Three pretests of the same posture } \\
\text { Three posttests of the same posture }\end{array}$ \\
\hline Step 3 & One-sample T-TEST & Whole pretests \& posttests of the same posture \\
\hline Step 4 & One-way ANOVA & $\begin{array}{l}\text { The whole three pretests } \\
\text { The whole three posttests }\end{array}$ \\
\hline Step 5 & Posthoc Scheffe & To compare total Scores of posttests \\
\hline
\end{tabular}

In this study, qualitative data, self-narratives, has also been used and was analyzed qualitatively.

\section{Findings and Discussion}

As it was mentioned in the previous sections, this study aims to investigate the impacts of bodily behaviors and certain kinds of sitting postures on EFL learners' moods in a language classroom. To this end, two kinds of instrumentations have been used to collect the data; The GMS (Denollet, 1993), and written self-narratives. In the first place, the results obtained from GMS will be elaborated.

\subsection{The Global Mood Scale (GMS)}

This questionnaire has been distributed eighteen times in nine sessions in this study; nine times as a pretest and nine times as a posttest. The whole study can be divided into three parts which investigate the impacts of ordinary postures, high-power posture, and low-power posture on learners' moods. Each posture has been examined three times/in three 
sessions. Assuming these, the results obtained from GMS can be analyzed in five steps.

\subsubsection{Step One}

In the first place, One-Sample t-test has been run nine times to investigate if there is a significant difference between the pretest and posttest of each session. As the results in Table 3 manifest, there is a significant difference between the pretest and posttest of each session implying that the data gained from pretests and posttest do not show similar results and that the treatment has had an impact on the participants.

Table 3. One-sample t-test of pretest and posttest for each session ( $N=15, \mathrm{df}=14)$

\begin{tabular}{|c|c|c|c|c|c|c|c|}
\hline \multirow[b]{2}{*}{ Posture } & \multirow[b]{2}{*}{ Session No. } & \multirow[b]{2}{*}{ Test } & & \multirow{2}{*}{$\begin{array}{c}\text { Sig. } \\
\text { (2-tailed) }\end{array}$} & \multirow{2}{*}{ Mean Difference } & \multicolumn{2}{|c|}{ 95\% Confidence Interval of the Difference } \\
\hline & & & & & & Lower & Upper \\
\hline \multirow{4}{*}{ Ordinary } & \multirow[t]{2}{*}{ 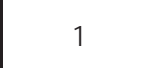 } & Pretest & 23.740 & .000 & 59.60000 & 54.2154 & 64.9846 \\
\hline & & Posttest & 12.820 & .000 & 56.60000 & 47.1305 & 66.0695 \\
\hline & \multirow{2}{*}{4} & Pretest & 30.293 & .000 & 57.46667 & 53.3979 & 61.5354 \\
\hline & & Posttest & 13.386 & .000 & 55.46667 & 46.5793 & 64.3540 \\
\hline \multirow{6}{*}{ High-power } & \multirow{2}{*}{7} & Pretest & 19.365 & .000 & 56.26667 & 50.0348 & 62.4986 \\
\hline & & Posttest & 18.754 & .000 & 56.46667 & 50.0090 & 62.9244 \\
\hline & \multirow{2}{*}{2} & Pretest & 16.124 & .000 & 57.80000 & 50.1117 & 65.4883 \\
\hline & & Posttest & 11.834 & .000 & 54.66667 & 44.7588 & 64.5745 \\
\hline & \multirow{2}{*}{5} & Pretest & 13.046 & .000 & 55.26667 & 46.1804 & 64.3529 \\
\hline & & Posttest & 12.033 & .000 & 50.26667 & 41.3067 & 59.2267 \\
\hline \multirow{8}{*}{ Low-power } & \multirow{2}{*}{8} & Pretest & 19.277 & .000 & 58.46667 & 51.9617 & 64.9717 \\
\hline & & Posttest & 16.197 & .000 & 55.80000 & 48.4110 & 63.1890 \\
\hline & \multirow[b]{2}{*}{3} & Pretest & 15.327 & .000 & 60.26667 & 51.8331 & 68.7002 \\
\hline & & Posttest & 10.067 & .000 & 37.60000 & 29.5891 & 45.6109 \\
\hline & \multirow{2}{*}{6} & Pretest & 23.323 & .000 & 60.06667 & 54.5428 & 65.5905 \\
\hline & & Posttest & 16.158 & .000 & 35.46667 & 30.7590 & 40.1744 \\
\hline & \multirow{2}{*}{9} & Pretest & 20.516 & .000 & 57.46667 & 51.4588 & 63.4745 \\
\hline & & Posttest & 15.863 & .000 & 33.93333 & 29.3454 & 38.5213 \\
\hline
\end{tabular}

\subsubsection{Step two}

As it was mentioned earlier, the impacts of each posture have been examined three times and in three sessions. Therefore, in the second place, One-way ANOVA was used to investigate the difference between three related pretests of each posture and three posttests of each posture as well. As Tables 4 and 5 show, there is no significant difference between three related pretests and three related posttests of each posture proving that although each posture was examined three times and in three different sessions, the results obtained are the same and homogenous.

Table 4. One-Way ANOVA to compare three pretests of each posture

\begin{tabular}{|c|cccccc|}
\hline Posture & & Sum of Squares & df & Mean Square & $F$ & Sig. \\
\hline Ordinary Posture & Between Groups & 76.844 & 2 & 38.422 & .405 & .669 \\
& Within Groups & 3983.067 & 42 & 94.835 & & \\
& Total & 4059.911 & 44 & & & \\
High-power Posture & Between Groups & 85.511 & 2 & 42.756 & .214 & .808 \\
& Within Groups & 8399.067 & 42 & 199.978 & & \\
& Total & 8484.578 & 44 & & & \\
& Between Groups & 73.200 & 2 & 36.600 & .244 & .784 \\
& Within Groups & 6287.600 & 42 & 149.705 & & \\
\hline
\end{tabular}

As Table 4 indicates, for instance in high-power posture sessions, there is no significant difference between three pretests taken $(p>05)$ proving that they produce consistent, accurate results and are administered under similar conditions. 
Table 5. One-Way ANOVA to compare three posttests of each posture

\begin{tabular}{|c|cccccc|}
\hline Posture & & Sum of Squares & df & Mean Square & $F$ & Sig. \\
\hline Ordinary Posture & Between Groups & 10.178 & 2 & 5.088 & .023 & .978 \\
& Within Groups & 9472.267 & 42 & 225.530 & & \\
& Total & 9482.444 & 44 & & & \\
High-power Posture & Between Groups & 256.311 & 2 & 128.156 & .506 & .607 \\
& Within Groups & 10638.667 & 42 & 253.302 & & \\
& Total & 10894.978 & 44 & & & \\
Low-power Posture & Between Groups & 101.733 & 2 & 50.867 & .436 & .650 \\
& Within Groups & 4902.267 & 42 & 116.721 & & \\
& Total & 5004.000 & 44 & & & \\
\hline
\end{tabular}

Similarly, the posttests taken do produce similar, consistent, and accurate results proving that the data collection procedure via GMS was done under similar conditions. As Table 5 demonstrates, there is no significant difference between three related posttests of each posture; ordinary posture $(p>.05)$, high-power/open posture $(p>.05)$, lowpower/closed posture ( $p>05)$.

\subsubsection{Step three}

In the third place, in order to achieve the total pretest and total posttest of each posture, the data collected from three related pretests and posttests of each posture have been added up together. After that, One-Sample t-test was run to see if there is a significant difference between total pretest and posttest of each posture. As Table 6 shows, there is a significant difference between total pretests and posttests proving that the treatment has had an impact on the participants.

Table 6. One-sample T-Test of Total pretests and posttest in each posture

\begin{tabular}{|c|c|c|c|c|c|c|c|c|}
\hline \multirow[t]{2}{*}{ Posture } & \multirow[t]{2}{*}{ Variables } & \multirow[t]{2}{*}{ Mean } & \multirow[t]{2}{*}{$\begin{array}{c}\text { Std. } \\
\text { Deviation }\end{array}$} & \multirow[t]{2}{*}{$\begin{array}{c}\text { Std. Error } \\
\text { Mean }\end{array}$} & \multirow[t]{2}{*}{$T$} & \multirow[t]{2}{*}{$\begin{array}{l}\text { Sig. (2- } \\
\text { tailed) }\end{array}$} & \multicolumn{2}{|c|}{$\begin{array}{l}\text { 95\% Confidence Interval of the } \\
\text { Difference }\end{array}$} \\
\hline & & & & & & & Lower & Upper \\
\hline Ordinary & Total Pretest & 173.533 & 23.12039 & 5.96966 & 29.069 & .000 & 160.7297 & 186.3370 \\
\hline Posture & Total Posttest & 168.333 & 36.85234 & 9.51523 & 17.691 & .000 & 147.9552 & 188.7415 \\
\hline High-power & Total Pretest & 171.533 & 35.26404 & 9.10514 & 18.839 & .000 & 152.0048 & 191.0619 \\
\hline Posture & Total Posttest & 160.733 & 41.47713 & 10.70935 & 10.009 & .000 & 137.7641 & 183.7026 \\
\hline Low-power & Total Pretest & 177.800 & 32.27383 & 8.33307 & 21.337 & .000 & 159.9273 & 195.6727 \\
\hline Posture & Total Posttest & 107.000 & 24.41311 & 6.30344 & 16.975 & .000 & 93.4805 & 120.5195 \\
\hline
\end{tabular}

\subsubsection{Step four}

In the final place, One-way ANOVA was again used to see if there is a significant difference between three postures. As Table 9 shows, there is no significant difference between the pretests of three postures $(p>.05)$, but there is a significant difference between the posttests. The results show that the data collected from pretests are the same and that the participants had had a similar mood and feeling before starting each session and treatment and that all of nine pretests were administered under similar conditions. However, having run the treatment, the participants had experienced a different feeling at the end of the class and treatment sessions.

Table 7. One-Way ANOVA Test to compare the whole Pretests and Posttests

\begin{tabular}{|c|cccccc|}
\hline Totals & & Sum of Squares & $d f$ & Mean Square & $F$ & Sig. \\
\hline Total & Between Groups & 307.378 & 2 & 153.689 & .164 & .850 \\
Pretests & Within Groups & 39475.867 & 4244 & 939.902 & & \\
& Total & 39783.244 & & & & \\
Total Posttests & Between Groups & 33534.044 & 2 & 16767.022 & 13.689 & .000 \\
& Within Groups & 51442.267 & 42 & 1224.816 & & \\
& Total & 84976.311 & 44 & & & \\
\hline
\end{tabular}




\subsubsection{Step Five}

In the last step, Posthoc Sheffe Test (Table 8) was used to compare the total scores of posttests of three postures. As this table shows, low-power posture has had a pretty different impact on EFL learners' moods and feelings.

Table 8. Scheffe Test for Total Posttests (Homogenous Subsets)

\begin{tabular}{|c|c|c|c|}
\hline Values & N & \multicolumn{2}{|c|}{ Subset for alpha = 0.05 } \\
\cline { 3 - 4 } & & 1 & 2 \\
\hline Low-power & 15 & 107.0000 & 160.7333 \\
High-power & 15 & & 168.3333 \\
Ordinary & 15 & & .839 \\
Sig. & & 1.000 & \\
\hline
\end{tabular}

Ordinary posture/high-power posture > low-power posture

As indicated in Table 7, there is a significant difference between the total scores of posttest of three postures, and as Table 8 shows, in comparison with ordinary posture, and high-power/open posture, the participants were more negatively affected by low-power/closed postures. In fact, there is no significant difference between total scores of posttests of ordinary and high-power postures showing that they have similar impacts on moods; however, as it is indicated lowpower postures have had negative impacts on participants' moods.

\subsection{Written self-narratives}

To gather the data, when each session was over, the researchers asked the students to write down their feelings. Students were to narrate what they were feeling after assuming those postures at the end of each session. Narrative analysis is a qualitative research method that is of high importance in understanding personal experience in the social sciences and educational research (Phillion \& He, 2007, as cited in Pishghadam \& Naji Meidani, 2012). Table 11 includes 22 mostly-used adjectives and themes by which the participants expressed their feelings in their self-narratives.

Table 9. Words and expressions by which the participants expressed their feelings

\begin{tabular}{|l|l|}
\hline High-power \& Ordinary posture sessions & Low-power posing sessions \\
\hline Interested & Low interest/unwilling/ intolerable/impatient \\
Energetic/active/volunteer/fresh & Low energy/ Physically weak/ sleepy/Tired/bored/ \\
Learn better & Learn fewer \\
Self-confidence/Self-esteem & Nervous/angry \\
concentration & Absent-minded/ \\
\hline
\end{tabular}

\subsubsection{Low-power posture}

The negative effects disclosed by the students in low-power posing sessions, in most of the cases, included feelings of tiredness and boredom: I feel tired, and this session was tiring. Sitting like this makes you feel bored and then the class becomes boring. Another student also expressed: I really feel tired and when I sit like that, I feel bored. One student wrote: This session was boring and in comparison with the previous sessions, it was unproductive; this posture is not good for a language class. In another comment one student said: In this kind of posture, we are not that comfortable and that is why we get tired soon.

Feeling sleepy is another mostly-expressed adjective found in participants' self-narratives: After 20 to 30 minutes, I felt sleepy and I wanted to take a rest. One student wrote: I became too tired, didn't understand today's lessens well, and felt sleepy. Another student stated: At the beginning of this session, everything was OK, but little by little I felt wearied and drowsy. Moreover, in another comment it has been mentioned: Definitely, the way you sit on the chair has a great impact on you; when I assumed this posture, I was really feeling drowsy and wanted to sleep right away. 
Some students found the situation intolerable: In comparison with the beginning of this session, I was not interested to listen to the teacher anymore as the class was becoming intolerable; I think I learned less than previous sessions. Another student also expressed restlessness and anger. Some participants were impatient: I checked the time several times and really wanted the class be over sooner; I think the way you sit has impact on one's moods. Another participant wrote: I felt impatient during the class and wanted to leave it since staying there was making me feel bored. Another student also expressed: Assuming this kind of posture makes you feel impatient and not willing to cooperate with classmates and answer the questions.

Some were physically weak and had low energy: At the beginning, I had plenty of energy, but after few minutes, I was running out of energy and didn't want to continue the class. One student wrote: I felt physically weak and absentminded as I felt a sharp pain in my shoulders and back that made me run out of energy. In their comments, some of the participants stated that low-power posing has had impact on their level of interest and willingness to learn as well as concentration on lessons: Assuming such a posture is unproductive and after 10 to 15 minutes, I was not eager anymore to learn and to stay in the class. Another student wrote: In comparison with previous sessions, I learned fewer and could not focus completely on what the teacher was teaching. One student mentioned: After few minutes, I became unwilling to answer the questions; it was not a good and joyful session.

\subsubsection{High-power posture}

Among the adjectives found in participants' self-narratives in high-power posing sessions, feelings of confidence, relaxation and joyfulness were the most prominent: When one assumes this posture, his moods change to a great extent, and then, he no longer feels tired or sleepy; today, I was more cheerful and relaxed. Another student wrote: After assuming this posture, I felt so good and confident; it really helps you be a dynamic and lively person in the class.

Some students stated that they were no longer meek listeners or compliant followers during the class. They acknowledged that they felt more energetic and cheerful and that they could speak and be active more which displayed the effectiveness of the posture in making them be more active in the class: I did not notice any change in my feelings at first, but little by little, I found myself more active as I volunteered several times to answer the questions.

\subsubsection{Ordinary posture}

The results obtained from the participants' self-narratives in ordinary posture sessions are nearly similar to the results obtained in high-power posture sessions. The reason, as they have stated, is that they were allowed to assume any posture they like and sit as they wish: I feel pretty good and cheerful as I did in the previous open posture sessions. One another student wrote: This session was better than the previous closed posture session, since I could be more active and learn more. Another student stated: This session was perfect and I didn't feel tired; I could concentrate on and understood the lessons better.

\section{Concluding Remarks}

As already pointed out, the aim of this study was to investigate and examine the impacts of specific sitting postures on learners' moods. In other words, in this study, we aimed at studying how and to what extent high-power (open) and lowpower (closed) postures may affect learners' moods. To this end, the data were collected through a mood adjective checklist as well as the students' self-narratives which was later analyzed for pinpointing the major themes and adjectives.

One of the important points to be taken into account is the significance of the effects. As the analyses of the GMSs and self-narratives revealed, low-power posing had great negative impacts on the participants' moods. As expected, lowpower (closed) postures increase one's anxiety, boredom, fatigue, and impatience level. The literature shows that assuming a closed posture is associated with an increase in unpleasant emotions (Carney et al., 2010; RossbergGempton \& Poole, 1993). Furthermore, compared to high-power posing, the participants of this study were more affected by low-power posing.

In comparison with low-power posture sessions, high-power posing appeared to make students be more eager to learn, feel more cheerful and relaxed, and be more dynamic which led to higher levels of self-confidence and productive class activity. This finding gives the seal of approval to the assertions made in previous studies (e.g., Arnette \& Pettijohn, 2012; Carney et al., 2010; Cuddy et al., 2012; Huang et al., 2011) supporting the fact that proper posture and expansive body positions (open and upright postures) are associated with an increase in the sense of power and likelihood of risk- 
taking. Similarly, as reviewed in the literature, Cuddy et al. (2012) found out that high-power posers reflect more confidence and have a more captivating speech.

A typical key example of focusing on a relaxed state of mind for language learners is Lozanov's Suggestopedia method "with students sitting in soft, comfortable seats in relaxed states of consciousness" (Brown, 2000, p. 105). That is to say, the type of furniture used in language classrooms is of high importance and can play a crucial role in providing a relaxed state of mind.

As reviewed in this study, the studies to date have not given enough attention to how physical postures and gestures may facilitate language learners' emotional states in a language classroom. In other words, assuming a lowpower posture decreases risk-taking and self confidence level as well as positive emotional states and increases the anxiety level and negative emotional states (Carney et al., 2010; Cuddy et al., 2012). However, the opposite pattern, high-power posing, seemed to have less impact on the participants.

Rossberg-Gempton and Poole (1993) found out that in comparison with males, females experienced a greater increase in unpleasant emotions when assuming a closed posture. Future research projects, however, need to be conducted to find out whether the results obtained in this study can be generalized to female learners, too, and whether they bear any same significant impact on learners' class activity as well as writing and reading skills, to name a few.

\section{References}

Anderson, C., \& Berdahl, J. L. (2002). The experience of power: Examining the effects of power on approach and inhibition tendencies. Journal of Personality and Social Psychology, 83, 1362-1377.

Anderson, C., \& Galinsky, A. D. (2006). Power, optimism, and risk-taking. European Journal of Social Psychology, 36, 511-536.

Arnette, S. L., \& Pettijohn II, T. F. (2012). The effects of posture on self-perceived leadership. International Journal of Business and Social Science, 3, 8-13.

Bem, D. J. (1972). Self-perception theory. In L. Berkowitz (Ed.), Advances in experimental social psychology (pp. 1-62). New York: Academic Press.

Bernstein, P. (1973). Recapitulation of ontogeny: A theoretical approach in dance movement therapy. In D. Plunk-Burdick \& S. Chaiklin (Eds.), Dance therapist in dimension: Depth and diversity (pp. 107-115). Columbia, MD: American Dance Therapy Association.

Brinol, P., Petty, R.E., \& Wagner, B. (2009). Body posture effects on self evaluation: a self validation approach. European Journal of Social Psychology, 39, 1053-1064.

Brown, H. D. (2000). Principles of language learning and teaching (4th ed.). NY: Pearson Education, Inc.

Carney, D. R., Cuddy, A. J., \& Yap, A. J. (2010). Power posing: Brief nonverbal displays affect neuroendocrine levels and risk tolerance. Psychological Science, 21(10), 1363-1368.

Carney, D.R., Hall, J.A., \& Smith LeBeau, L. (2005). Beliefs about the nonverbal expression of social power. Journal of Nonverbal Behavior, 29, 105-123.

Cesario, J., \& McDonald, M. M. (2013). Bodies in context: Power poses as a computation of action possibility. Scoial Cognition, 31(2), 260-274.

Churches, R., \& Terry, R. (2007). NLP for teachers: How to be a highly effective teacher. USA: Crown House Publishing Company.

Clay, L., Couture, N., \& Nigay, L. (2007). Emotion capture based on body postures and movements. Presented at International Conference on Computing and e-systems, Hammamet, Tunisia, 2007.

Corazza, S., M undermann, L., Chaudhari, A. M., Demattio, T., Cobelli, C., \& Andriacchi, T. P. (2006). A markerless motion capture system to study musculoskeletal biomechanics: Visual hull and simulated annealing approach. Annals of Biomedical Engineering, 34(6), 1019-1029.

Cuddy, A. J. C., Wilmuth C. A., \& Carney, D. R. (2012). The Benefit of power posing Before a High-Stakes Social Evaluation. Harvard Business School Working Paper, No. 13-027.

Dael, N., Goudbeek, M., \& Scherer, K. R. (2013). Perceived gesture dynamics in nonverbal expression of emotion. Perception, 42, 642657.

Darwin, C. (1890). The expression of the emotions in man and animals. London: John Murray.

Denollet, J. (1993). Emotional distress and fatigue in coronary heart disease: The global mood scale (GMS). Psychological Medicine, 23(1), 111-121.

D'Mello, S. K., Chipman, P., \& Graesser, A. C. (2007). Posture as a predictor of learner's affective engagement. In D. S. McNamara \& J. G. Trafton (Eds.), Proceedings of the 29th annual cognitive science society (pp. 905-910). Austin, TX: Cognitive Science Society.

Docherty, G. J., \& Ladd, D. R. (Eds.). (1992). Papers in laboratory phonology II: Gesture, Segment, prosody. UK: Cambridge University Press.

Duclos, S. E., Laird, J. D., Schneider, E., Sexter, M., Stern, L., \& Van Lighten, O. (1989). Emotion-Specific Effects of Facial Expressions and Postures on Emotional Experience. Journal of Personality and Social Psychology, 57 (1), 100-108.

Efron, D. (1972). Gesture, Race and culture. The Netherlands: Mouton \& Co. N.V., Publishers, The Hague.

Ekman, P. (1999). Basic emotions. In T. Dalgleish, \& M. Power (Eds.). Handbook of cognition and emotion (pp. 45-60). Sussex, U.K.: John Wiley \& Sons, Ltd. 
Flack, W. F., Laird, J. D., \& Cavallaro, L. A. (1999). Separate and combined effects of facial expressions and bodily postures on emotional feelings. European Journal of Social Psychology, 29, 203-217.

Flack, W. F., Jr, Laird, J. D., Cavallaro, L. A., \& Miller, D. R. (1998). Emotional expression and experience: A psychosocial perspective on schizophrenia. In W. F. Flack, Jr., \& J. D. Laird (Eds), Emotions in psychopathology: Theory and research (pp. 315 \pm 322$)$. New York: Oxford University Press.

French, J., \& Raven, B. (1959). The bases of social power. In D. Cartwright (Ed.), Studies in social power (pp. 150-165). Ann Arbor, MI: Institute for Social Research.

Gregersen, T. S. (2007). Language learning beyond words: Incorporating body language into classroom activities. Reflections on English Language Teaching, 6(1), 51-64.

Guinote, A. (2007). Power and goal persuit. Personality and Social Psychology Bulletin, 33 (8), 1076-1087.

Gullberg, M. (2010). Methodological reflections on gesture analysis in second language acquisition and bilingualism research. Second Language Research, 6(1), 75-102.

Harmon-Jones, E. , \& Peterson, C. K. (2009). Supine body position reduces neural response to anger evocation. Psychological Science, 20(10), 1209-1210.

Hegel, G. W. F. (1971). Hegel's philosophy of mind. Oxford, UK: Clarendon.

Huang, L., Galinsky, A. D., Gruenfeld, D. H., \& Guilory, L. E. (2011). Powerful postures versus powerful roles: Which is the proximate correlate of thought and behavior? Psychological Science, 22(1), 95-102.

Izard, C. E. (1994). Innate and universal facial expressions: Evidence from developmental and cross-cultural research. Psychological Bulletin, 115(2), 288-299.

James, W. (1980). The principles of psychology. New York: Holt. Keltner, D., Gruenfeld, D. H., \& Anderson, C. (2003). Power, approach, and inhibition. Psychological Review, 110, 265-284.

Kendon, A. (2000). Language and gesture: Unity or duality? In D. McNeil (Ed.), Language and gesture (pp. 47-62). UK: Cambridge University Press.

Laird, J. (1974). Self-attribution of emotion: The effects of expressive behavior on the quality of emotional experience. Journal of Personality and Social Psychology, 29, 475-486.

Macedonia, M., \& Kriegstein, K. V. (2012). Gestures enhance foreign language learning. Biolinguistics, 6(3-4), 393-416.

McHugh, J. E., McDonnell, R., O'Sullivan, C., \& Newell, F. N. (2010). Perceiving emotion in crowds: The role of dynamic body postures on the perception of emotion in crowded scenes. Experimental Brain research, 204, 361-372.

McIntosh, D. N. (1996). Facial feedback hypothesis: Evidence, implications, and directions. Motivation and Emotion, 20, $121-147$.

Mehrabian, A. (1971). Silent messages. Belmont, CA: Wadsworth Publishing Company, Inc.

Mota, S., \& Picard, R. W. (2003) Automated posture analysis for detecting learner's interest level. 1st IEEE workshop on computer vision and pattern recognition, CVPR HCl, (TR 574).

Nagel, F., Maurer, M., \& Reinemann, C. (2012). Is there a visual dominance in political communication? How verbal, visual, and vocal communication shape viewers' impressions of political candidates. Journal of communication, 60(5), 833-850.

Neil, S., \& Caswell, C. (1993). Body language for competent teachers. London: Routledge.

Nielson, E. S., Canalis, L. A., \& Tejera, M. H. (2004). Hand gesture recognition for human-machine interaction. Journal of WSCG, 12(13), 395-402.

Nierenberg, G. I., \& Calero, H. H. (1971). How to read a person like a book. New York: Hawthorn Books.

Osho, S. A. (2011). The uniqueness of African means of communication in a contemporary world. Retrieved on October 25, 2013 from http://www.africanoutlookonline.com/index.php

Pease, A. (1981). Body language: How to read other thoughts by their gestures. London: Sheldon Press.

Pishghadam, R., \& Naji Meidani, E. (2012). A critical look into critical pedagogy. Journal for Critical Education Policy Studies, 10(9), 464484.

Richards, J. C., \& Schmidt, R. (2002). Longman dictionary of language teaching and Applied linguistics (3rd ed.). London: Longman (Pearson Education).

Riskind, J. H. (1984). They Stoop to Conquer: Guiding and Self-Regulatory Functions of Physical Posture After Success and Failure. Joural of Personality and Socal Piychology, 47(3), 479-493.

Riskind, J. H., \& Gotay, C. C. (1982). Physical posture: Could it have regulatory or feedback effects on motivation and emotion? Motivation and Emotion, 6, 273-298.

Ronay, R., \& Hippel, W. V. (2010). Power, testosterone, and risk-taking. Journal of Behavioral Decision Making, 23, 473-482.

Rossberg-Gempton, I. E., \& Poole, G. D. (1993). The effect of open and closed postures on pleasant and unpleasant emotions. The Arts in Psychotherapy, 20, 75-82.

Schnall, S., \& Laird, J. D. (2003). Keep smiling: Enduring effects of facial expressions and postures on emotional experience and memory. Cognition and Emotion. 15(1), 27-56.

Smith, J. (2004). Posing portrait photography: A head-to-toe guide. New York: Amherst Media, Inc.

Smith, P. K., \& Bargh, J. A. (2004). Nonconcious effects of power on basic approach and avoidance tendencies. Social Cognition, 26(1), 1-24.

Stepper, S., \& Strack, F. (1993). Proprioceptive determinants of emotional and nonemotional feelings. Journal of Personality and Social Psychology, 64, 211-220.

Taleghani-Nikazm, C. (2008). Gestures in foreign language classrooms: An empirical analysis of their organization and function 
selected. In M. Bowles et al. (Eds.), Proceedings of the 2007 second language research forum (pp. 229-238). Somerville, MA: Cascadilla Proceedings Project.

Tiedens, L.Z., \& Fragale, A.R. (2003). Power moves: Complementarity in dominant and submissive nonverbal behavior. Journal of Personality and Social Psychology, 84, 558-568.

Tomkins, S. S. (2008). Affect, imagery, consciousness. NewYork: Springer.

Wilson, M. (2002). Six views of embodied cognition. Psychonomic Bulletin \& Review, 9 (4), 625-636. 